Revista Iberoamericana. $\quad$ Vol. LXII, Núm. 175, Abril-Junio 1996; 477-483

\title{
LA DIALÉCTICA DE LA ANTIPATÍA: COLÓN, BOLÍVAR Y SANTANDER EN LA OBRA DE GARCÍA MÁRQUEZ
}

\author{
POR \\ GeRmÁn D. CARRILlo \\ Marquette University
}

En el interesante libro García Márquez habla sobre García Márquez que editó Rentería Mantilla en Bogotá en 1979 se cuenta, entre muchas otras anécdotas literarias, que preguntado el autor sobre las dos figuras de la historia que le parecieran más "odiosas", éste se apresuró a responder sin ninguna vacilación: Colón y Santander. Santander, el malo, es aquí obviamente la antinomia de su querido Bolívar. ${ }^{1}$

Esto dicho en 1979 tal vez exija de cierta cronología adicional para hacerlo más explícito: estamos sólo a cuatro años del segundo gran éxito novelístico sin precedentes de El otoño del patriarca (1975), a doce años desde el jubiloso acontecimiento que constituyó la aparición de Cien años de soledad (1967), y todavía muy distantes de la excitación y el encono que produciría la celebración del Quinto Centenario del encuentro de América y Europa. En la superficie casi se podría afirmar que esta observación, por aguda que parezca, no es más que otra de las ingeniosas ocurrencias del celebrado autor. Sin embargo, se requerirían once años más y la publicación de otra gran novela como es El general en su laberinto (1989) para que el sentido total de esta sencilla aseveración, casi puesta en forma de adivinanza perspicaz al descuido, revelara todo el mensaje cifrado de su muy honda y peculiar interpretación de la historia americana, vista desde su privilegiada posición de gran escritor de las postrimerías del siglo XX con una respetable audiencia universal a su alcance. ${ }^{2}$

\footnotetext{
${ }^{1}$ García Márquez habla de García Márquez (entrevista) (Bogotá: Alfonso Rentería Mantilla Editores, 1979) 114-115. Reiteración de la antipatía por Colón aparece profusamnete comentada en El olor de la guayaba: conversaciones con Plinio Apuleyo Mendoza (Bogotá: Ed. La Oveja Negra, 1982), particularmente en la sección dedicada a la semblanza personal sobre los modelos del dictador superpuestos en El otoño del patriarca, páginas 83-91. El autor lo ha comentado también en otras entrevistas.

${ }^{2}$ Gabriel García Márquez, El general en su laberinto (Madrid: Ed. Mondadori, 1989). Conviene anotar que con anterioridad a la publicación de esta novela, el poeta y narrador colombiano Alvaro Mutis había escrito un relato titulado El último rostro (1978) que también es una biografía de Bolívar agonizante en su viaje final por el río Magdalena. El reconocimiento de García Márquez a su colega y amigo del "exilio mexicano" fue tan grande que le dedicó la novela con estas expresas palabras: "A Alvaro Mutis, quien me regaló esta historia". Por otra parte, otro escritor colombiano de creciente renombre, Fernando Cruz Kronfly, ya había publicado para 1985 una novela que tituló La ceniza del Libertador (Bogotá: Ed. Planeta, 1985) que coincidencialmente trata del mismo tema. Aparecen aquí algunos de los textos que
} 
Empezaremos por Colón; seguiremos después con el binomio que constituyen Bolívar y Santander antes de concluir nuestro estudio.

Aunque la presencia de Colón en la obra de García Márquez ha venido siendo analizada por varios estudiosos, entre quienes se encuentran los profesores González-Echevarría y Palencia-Roth, conviene que resumamos aquí lo que se ha escrito sobre el tema. ${ }^{3}$

González-Echevarría se ha ido adentrando gradualmente en el tema a través de sucesivos estudios sobre el Barroco que culminan con la reciente aparición del libro Myth and Archive: A Theory of Latin American Narrative (1992). Este novedoso enfoque sugiere, entre otras cosas, la creación de una formidable conciencia ficcional que hurga y desentraña con gran meticulosidad entre los intricados pliegues y repliegues de la crónica-historia americana en busca del necesario principio y fondo de estos cinco siglos que empiezan a contar el 12 de octubre de 1492. Establecidos estos elementos de juicio, el investigador nos propone su intrigante teoría del principio - mítico claro está-y su necesario referente que lo corrobore - el archivo - imagen de la profecía, que aquí es el texto mismo y que para el caso americano no es otra que la novela en toda su increíble e insospechada fuerza. La novela sí -síntesis de la gesta, de la historia, de la fábula y de la misma crónica europea-, se convierte entonces en el obvio depositario de todo el patrimonio cultural desparramado en cinco siglos de incesante encuentro y fusión de dos mundos: el Viejo, Europa, y el Nuevo, América. La lectura del primer capítulo que se titula $A$ Clearing in the Jungle: from Santa Mónica to Macondo (1-42) tiene el inusitado mérito de establecer un emparentamiento causal, por supuesto mítico, entre el final pesimista de Los pasos perdidos (1953) de Alejo Carpentier justamente con el alucinante comienzo edénico de Cien años de soledad (1967) a través de la imprevista función de vasos comunicantes que viene a ser lo "real maravilloso americano" de cuño netamente carpenteriano que GonzálezEchevarría había investigado con anterioridad

más tarde trataría García Márquez tales como el viaje por el río oscuro del recuerdo, las alucinaciones disfrazadas de visiones, la obsesión por el pasaporte que no tiene para poder salir del país, la ironía que representan las palomas mensajeras, lo único que le apetece al héroe no obstante que son sus únicos medios para comunicarse con el mundo más allá de su lecho, la sarcástica alusión a los navíos de guerra llamados aquí "Bolívar" y "Santander" y que "constituyen graves peligros para la navegación", la locura alarmante del héroe, etc. Alvaro Pineda Botero hace una justa reseña del libro de Cruz Kronfly en su obra titulada Delmito a la posmodernidad: la novela colombiana de finales del siglo XX(Bogotá: Tercer Mundo Editores, 1990) 157-158. Lo realmente curioso es que García Márquez no haga ninguna alusión al texto de Cruz Kronfly.

${ }^{3}$ Roberto González-Echevarría exploró este asunto primero en su artículo "Cien años de soledad: The Novel as Myth and Archive", aparecido en $M L A, 99 / 2$ (marzo de 1984). El mismo artículo sería luego incluido en la antología que publicó el profesor Harold Bloom titulada Gabriel García Márquez (New York-Philadelphia: Chelsea House Publishers, 1989), 49-63. Sin embargo, donde mejor y más definitivamente logra profundizar en el tema es en su reciente libro Myth and Archive: A Theory of Latin American Narrative (Cambridge University Press, 1992). La familiaridad del autor con los temas recurrentes de Carpentier y del Barroco americano viene corroborada por sus ensayos y libros entre los que destaca The Pilgrim at Home (Ithaca: Cornell University Press, 1977). 
en su libro Alejo Carpentier: The Pilgrim at Home. Las apretadas notas que escribey reescribe el narrador y protagonista de Los pasos perdidos se convertirán así en el archivo fundacional y referente primordial de toda la novela-historia hispanoamericana incluyendo grandes hitos como La guerra del fin del mundo (1980) de Vargas Llosa, Terra nostra (1976) de Carlos Fuentes y la misma Cien años de soledad.

Sobre este macrotexto indudablemente se hablará mucho en lo que nos queda del siglo y constituye en verdad un desbloque esclarecedor y definitorio en la interpretación de la vidahistoria-novela americana desde el mismísimo Diario de Colón, o sea, desde el lejano arcano mitificado.

En la misma década anterior, el profesor Palencia-Roth propuso, en diversos estudios sucesivos, aplicaciones a las teorías estético-filosóficas de corte heideggeriano, vistas bajo la lupa de la interpretación histórica a este lado del Atlántico. Siguiendo las premisas de Gadamer y en cierto punto de Habermas, discípulos del maestro Heidegger, se postula a modo de máxima recursiva, que todo es cuestión de horizonte o campo de visión y que si éste cambia, cambiará necesariamente la interpretación que se le dé a los hechos examinados. Es, en cierto modo, un nuevo replanteamiento del perspectivismo orteguiano de unas décadas anteriores, aplicado a la historia y al hombre americanos, al ser y a su tiempo. Palencia-Roth se vale de lo que él denomina prisma de conciencia - horizonte heideggeriano-aplicado en cada caso a Colón y a Bolívar. Se trata en cada caso de descifrar qué es eso que descubre el prisma de conciencia del gran novelista, cómoda pero tambíen críticamente instalado en la conciencia ficcional de dos seres extraordinarios: Colón y Bolívar. ${ }^{4}$

La perspectiva visual de García Márquez no es otra que la del americano mestizo, caribeño, escritor de ficciones en las postrimerías del siglo XX, anticolonialista puro, amante nato de la libertad sin condiciones y para quien la figura que proyecta el Colón del Diario, el Colón entronizado por la historia oficial es antipática y odiosa, además de ser culpable en sumo grado del gran malentendido histórico en que ha quedado sumida toda la historia americana ante los ojos europeos. La paradoja para el escritor queda expuesta en estos términos: he aquí un hombre renancentista que viene al Nuevo Mundo en busca de verdades universales y quien, metamorfoseado por las circunstancias imprevisibles de su odisea, se convierte en el primer escritor de la realidad americana y a la vez en su primer gran desfigurador al interpretar tendenciosamente esa realidad que ven sus ojos, según su antojo y conveniencia, sumiendo de paso y para siempre todo un continente en una crisis de identidad de la que todavía no ha podido salir en más de ciento ochenta años de vida republicana irregular, matizados por el fenómeno de la dictadura.

Tales esfuerzos saldrían a la luz pública en circunstancias tan especiales como fue el discurso de recepción del Premio Nobel de 1982 cuando pedía de los europeos para quienes

\footnotetext{
${ }^{4}$ Las publicaciones del profesor Palencia-Roth sobre estos temas incluyen: el artículo "Prism of Consciousness: The 'New Worlds' in Columbus and García Márquez", aparecido primero en Critical Perspectives on Gabriel Garcia Márquez, Ed. B. Shaw y N. Vera-Goodman, 1986 y posteriormente incluido también en la antología de H. Bloom ya mencionada, páginas 243-256. Más detalladamente explicado se halla en su artículo: "Three Metamorphoses of Myth in The Autumn of the Patriarch", publicado en la antología del profesor Julio Ortega titulada Gabriel García Márquez and the Powers of Fiction (University of Texas Press, 1988), 34-60.
} 
hablaba mayor comprensión, mayor tolerancia y paciencia de hermanos mayores, mayor humildad en el modo de juzgar a todo un continente que todavía no ha alcanzado la madurez política europea. ${ }^{5}$ Entonces como hoy, García Márquez creía que sólo mediante la corrección del malentendido secular podría Latinoamerica salir poco a poco de su marasmo. En el discurso llamaría a estos elementos el "tamaño de nuestra soledad", o el "nudo de nuestra soledad", o el "precio" que hemos tenido que pagar todos para ser medio entendidos. Lo haría también en la primera página de Cien años de soledad cuando sostenía que el "mundo era tan reciente que muchas cosas carecían de nombre y para nombrarlas había que señalarlas con el dedo". 6 Pero donde mejor plantea esta distorsión es en la inversión imaginaria, pero no menos reveladora de su propósito,del primer encuentro narrado desde este lado, o sea, desde la perspectiva del indio caribe quien no acaba de comprender el porqué de tanta algarabía. Para lograrlo, García Márquez se reviste como nadie de los mágicos poderes que concede la intertextualidad como arma de dos filos en circunstancias también extraordinarias. Veamos cómo se efectúa el saqueo del Diario de Colón en El otoño del patriarca:?

... que habían llegado unos forasteros que parloteaban en lengua ladina pues no decían el mar sino la mar y llamaban papagayos a las guacamayas, almadíes a los cayucos, azagayas a los arpones, y que habiendo visto que salíamos a recibirlos nadando en torno de sus naves, se encarapitaron en los palos de la arboladura y se gritaban unos a otros que mirad que bien hechos, de muy fermosos cuerpos y muy buenas caras, y los cabellos gruesos y casi como sedas de caballos, y habiendo visto que estamos pintados para no despellejarnos por el sol se alborotaron como cotorras mojadas gritando que mirad que de ellos se pintan de prieto, у ... (...) y nosotros no entendíamos porqué carajos nos hacian tanta burla, mi general, si estábamos tan naturales como nuestras madres nos parieron y en cambio ellos estaban vestidos como la sota de bastos a pesar del calor, que ellos dicen la calor. (...) y gritaban que no entendían en lengua de cristianos cuando eran ellos los que no entendían lo que gritábamos. (...) (...) y como vimos que eran buenos servidores y de buen ingenio nos los fuimos llevando hacia la playa sin que se dieran cuenta, pero la vaina fue que entre cámbieme esto por aquello y le cambio esto por esto otro se formó un cambalache de la puta madre ... y hasta querían cambiar a uno de nosotros por un jubón de terciopelo para mostrarnos en la Europas ... (44-45).

Lo que a García Márquez le parece incomprensible de Colón es su doblez manifiesta en el lenguaje; o sea, mientras decía una cosa a los marineros, otra muy distinta escribía en su Diario. Es decir que al describir la América que veían sus ojos europeos, la desvirtuaba también a conciencia, la saqueaba a maravilla. En tanto que perseguía fama, fortuna y honor, como cualquier mortal renacentista, aparentaba en la superficie humildad, desprendimiento y en cierto modo, desprecio por los poderes terrenales. En la terminología de García Márquez, América vendría a ser la víctima de esta doble visión interesada. Tomando como base este argumento, el autor sostiene que su misión de escritor de hacer más comprensible esta nueva realidad que ya cumple cinco siglos, se ve muchas veces menguada o rebatida por lo que

\footnotetext{
5 El Discurso de recepción del Premio Nobel, 1982, se tituló "La soledad en la América Latina", y ha sido tomado de la revista 'Cromos, 3.387 (Bogotá, 14 de diciembre de 1982), 14-15.

${ }^{6}$ Gabriel García Márquez, Cien años de soledad (Buenos Aires: Ed. Suramericana, 1967) 9.

${ }^{7}$ Gabriel García Márquez, El otoño del patriarca (Barcelona: Ed. Plaza y Janés, 1975) 44-45.
} 
denomina el "iceberg-effect" todavía muy presente aunque sumergido en la conciencia del europeo corriente. Desde el Diario, continúa, América quedaría desposeida de su identidad real para poder ser sometida a la interpretación voluntariosa (europea) que vino desde fuera. Es la pérdida de lo que Stephen Greenblatt llamaría más tarde "marvelous possessions" entre las que el lenguaje propio, como horizonte, es sin duda una de las más fuertes repercusiones, puesto que la conciencia de estos pueblos quedó a merced del interpretador (ex. fránces, inglés, español, portugués, etc.) y nunca, o casi nunca, del interpretado. ${ }^{8}$ Así que, siguiendo los tres pasos propuestos por Greenblatt, de la identificación inicial de América - primer paso- se pasaría a la reducción de todo lo que no estuviese contemplado en los códigos del Viejo Mundo y de allí a la eliminación - paso final-de todo lo que no estuviese contemplado en el prisma de conciencia de los descubridores. La Conquista del Nuevo Mundo ha sido lograda plenamente, satisfecha sí, pero a costa de un gran precio, además de injusto. Colón, visto bajo esta perspectiva, no podría ser nunca simpático ante los ojos del autor americano quien se considera maltratado. En un contexto filosófico se podría resumir diciendo que los archivos - tanto el de Sevilla como el de Simancas - prevalecen y se imponen mientras que América, por fuerza silenciada o muda, no alcanza al estadio del discurso codificado que le correspondía.

Siguiendo las premisas de González-Echevarría en su estudio de Cien años de soledad como mito y como arcano y, extendiendo el paralelismo un paso más allá, creemos que uno de los mayores méritos narrativos de El general en su laberinto ha sido la sutilísima instauración de una conciencia histórica ficcional que no es otra cosa que la del mismo Bolívar, visto como sintesis viva de tres siglos de colonización, ahora estancados en un punto muerto, desde la cual el personaje contempla simultáneamente su pasado caduco por repetición del modelo colonial momificado, su presente que es su momento histórico sin salida —obvia imagen de su laberinto personal-, así como su futuro visto únicamente en lo que tiene de remotísima posibilidad - ¿salida del laberinto? - que de alguna manera impensada hasta ahora justificaría el inmenso sacrificio de toda una vida, una fortuna, una salud, desperdiciadas en nombre de una vaga y escurridiza causa libertadora.

Aquí, como antes en Colón, la América colonial moribunda y la nueva edad republicana naciente, siguen siendo el pre-texto para la biografía ficcional de Bolívar en sus últimos ocho meses de vida, a la vez que constituyen el nuevo texto, objeto de nuestra lectura. Y sin

\footnotetext{
${ }^{8}$ Stephen Greenblatt, Marvelous Possessions: the Wonder of the New World (The University of Chicago Press, 1991) 202. González-Echevarría escribió una reseña de este libro titulada "Europeans in Wonderland" publicada por el New York Times Book Review (16 de febrero de 1992) 22-23. Esta reseña es abiertamente desfavorable al libro de Greenblatt. El crítico cree que mientras es verdad lo que se dice de "marvelous", de "wonders" y de "possessions", desde el punto de vista del colonialismo europeo, poco hay de prodigioso ni de maravilloso desde el punto de vista del indio americano para quien el sufrimiento, la desposesión de su tierra, de su historia y de su misma identidad empezó justamente con la llegada de los europeos. Además de censurar la falta de profundidad en la explicación de las posesiones maravillosas, González-Echevarría se resiente de la insignificancia marginal que Greenblatt da en su libro a lo real maravilloso americano.
} 
embargo, texto y pre-texto corren el riesgo de no pasar de ser mera fabulación como parte de la inevitable tentación del novelista en su nuevo papel de antihistoriador que intenta la narración de esta nueva fundación desde sus comienzos - la Gran Colombia: 1819-1830, o sea, desde la perspectiva única de la conciencia que es el Bolívar garciamarquiano.

Palencia-Roth sostiene con sobrada razón que la colonización española en el momento de la aparición de Bolívar en escena estaba atravesando por su tercera y última faceta de su historia interna que corresponde al momento de la rebelión y emancipación. Es justo el momento en el que, siguiendo su terminología, el prisma de conciencia del americano nativo echa al colonizador extranjero y recupera para sí la tierra. En su enfoque hermenéutico, el personaje del patriarca, en pleno otoño, desmitifica así el papel del poder colonial para forzar otra interpretación, americana en todo caso, de la historia.

El Bolívar de García Márquez, irónicamente mitificado por la mismísima historia republicana, aparece aquí en su más escueta humanidad: pobre, enfermo y sobre todo incomprendido. La novela, ironía supina, obliga a verlo como el ser trágico y patético que era en esos ocho meses postreros de 1830. Podría verse incluso como una nueva e ingeniosa versión del Colón de tres siglos anteriores, despojado de su Diario, metáfora de su ficción. Es un ser inmerso en su contexto histórico, es verdad, pero también humanizado y acabado.

El personaje de Bolívar, como los de Borges a las puertas del laberinto (ex. el mundo, el desierto, el otro, la línea, etc.), está irremediablemente atrapado en el prisma de su poderosa conciencia individualizadora muy capaz de comprender que sólo la muerte que arrastra sus pasos lentos y que tarda, será la única salida posible a esta situación límite en que se ha convertido la romántica causa emancipadora de antaño desde aquel día lejano en las afueras de Roma hasta hoy aquí moribundo en San Pedro Alejandrino en las afueras de Santa Marta.

Ese mismo ente visionario le permitirá entrever más allá del tiempo convencional de los demás, a la par que le hunde en una cierta dialéctica trágica pascaliana - esa causa por la que luchó ¿alguna vez tuvo sentido?- que todo su esfuerzo ha sido vano e inútil en virtud del gran malentendido en que se ha metamorfoseado su obra. Adquiere ahora la diáfana conciencia de que, habiendo logrado desalojar al colonizador extranjero, no existe en el horizonte un plan viable en otro personaje continuador, menos ahora que su querido Sucre ha sido eliminado brutalmente de la escena y que sólo queda Santander, allá en el destierro, espantado como el buitre, pero dispuesto a volver cuando las circunstancias así lo aconsejen. He aquí la otra cara del segundo odioso, ${ }^{9}$ Santander, como destructor y desvirtuador del gran sueño visionario bolivariano. He aquí también el cordón umbilical que ata de alguna forma lógica en el prisma de conciencia del autor al primero de los odiosos (Colón) con el segundo (Santander), visto

\footnotetext{
${ }^{9}$ Para una mejor comprensión del sentido que tiene el apodo Casandro aplicado al general Santander, visto en la novela como el archienemigo del héroe garciamarquiano, convendría ver el capítulo final del libro de Isabel Rodríguez-Vergara titulado El mundo satírico de García Márquez (Madrid: Ed. Pliegos, 1991) 230. Dicho capítulo se titula "El general en su laberinto: la escritura como exorcismo", páginas 197-219. Rodíguez-Vergara, siguiendo de cerca las premisas baktianas sobre la carnavalización, afirma que el Santander garciamarquiano tiene conscientemente acentuados los rasgos negativos como una manera de "hacerle justicia", ficcional en todo caso, a su héroe entrañable en este recorrido por el río Magdalena abajo que él mismo hiciera por lo menos once veces en su época de estudiante en Zipaquirá y Bogotá. El nombre Casandro tiene, por supuesto, antecedentes históricos en el reyezuelo macedónico que terminó por destruir el gran sueño de imperio de Alejandro Magno.
} 
aquí como otra faceta de Colón, el desvirtuador. Se cierra así el ciclo que necesitaría once años de apertura para expresarse y completarse. Bolívar queda atrapado en el laberinto de su obra misma y sin ninguna posibilidad de desandar ni deshacer los pasos que lo llevarían hasta esta encrucijada.

García Márquez efectúa ante el lector una doble y rápida pirueta novelesca: por un lado desmitifica la historia consagratoria de la que sale ahora un Bolívar nuevo pero indefenso, menguado en todo, incluso en peso y estatura, imposibilitado para todo, incluso para comer; por otro lado, impone y obliga a una nueva interpretación que, aunque no muy halagüeña para los bolivarianos incondicionales del mito, está mucho más acorde con Bolívar, el hombre, visto desde hoy, desde nuestra obligada y abigarrada carnavalización de la historia.

La postura del autor no da lugar a ninguna ambigüedad: se plantea en el terreno convencional -América versus Europa- es verdad, y ante ello se pone del lado americano sin ambajes. Sin embargo, intenta cerrar con la imagen unificadora del sueño de Bolívar (el panamericanismo en su mejor sentido) la brecha que abriera Colón tres siglos antes, proponiéndoselo o no.

\section{IV}

Los dos grandes incomprendidos (Colón y Bolívar) lo son sólo en función del horizonte o prisma con que se les haya mirado. Es decir, que mientras Colón es un héroe europeo y tal vez no podría ser visto de otro modo, Bolívar lo es desde el lado americano, y tal vez tampoco podría ser visto de otro modo. Sin embargo, en el discurso garciamarquiano, el lastre colonialista resulta tan fuerte, $\tan$ pesado y todavía tan europeo que exige aun hoy en día que veamos a Colón como se le ve desde la otra orilla, forzando así las perspectivas. El autor se resiente de todo ello y lo expresa de la manera que él conoce mejor: parodiando y ridiculizando la historia oficializante, pero obligando también a una nueva e innnegablevisión enriquecedora. 
